\title{
Seismic Analysis of Shallow Tunnel in Bad Ground with the Numerical Simulation Method
}

\author{
Guo Zihonga , Luo Ruyue a , Li Tangyong ${ }^{\mathrm{a}}$, Zou Gaoqiang ${ }^{\mathrm{b}}$, Gong Han ${ }^{\mathrm{a}}$, and He Jialin ${ }^{\mathrm{a}}$ \\ School of Sichuan Agricultural University, Dujiangyan 611830, China \\ a379492135@qq.com, b2359926625@qq.com
}

Keywords: Shallow tunnel; numerical simulation; seismic analysis; bad ground

Abstract: Seismic damages of the tunnel show that surrounding rock of shallow tunnel is mostly of a low grade and its stability is poor. The shallow tunnel is susceptible to earthquake. The dynamic calculation of the shallow tunnel in bad ground is performed by establishing a two-dimensional numerical model and using viscoelastic artificial boundary to simulate the dynamic boundary. Acceleration distribution in surrounding rock, the inner force variation of lining structure and the seismic displacement of surrounding rock are all analysed. The results show that the acceleration of surrounding rock increases with the decrease of the distance from the ground surface. The acceleration at ground surface is about 1.5 times at vault of tunnel and the acceleration of surrounding rock is gradually reduced from the tunnel structure to the model boundary. The horizontal displacement of surrounding rock keeps decreasing when its location moves away from the tunnel, and the displacement at each point increases with the shaking time and shaking intensity. Under seismic loading, the axial force and bending moment change most obviously at spandrel and arch foot of tunnel where the lining structure should be strengthened.

\section{Introduction}

In recent years, with the gradual development of the "One Belt and One Road" strategy and the rapid development of the national economy, China has increased its investment in the construction of the transportation sector. With the continuous expansion of the construction scale of highways, railways and subways, shallow tunnels are also commonly found in practical projects. The investigation of the "512"earthquake ${ }^{[1-3]}$ in Wenchuan indicates that the damage of hard rock and deep tunnels is slight while soft rock and shallow tunnels' damage is more serious. Lots of surveys have shown that shallow and soft rock tunnels have poor stability under earthquake, and they are easily prone to landslides in the tunnel portal, collapse of surrounding rock and other hazards, which will result in a large number of casualties and property losses. Therefore, it is necessary to further improve the seismic stability analysis of shallow and soft rock tunnel.

Finite element numerical calculation can not only overcome the deficiencies of model test but also can be compared with the theoretical calculation to verify its correctness. Therefore, the numerical 
simulation has been gradually favored and applied by scholars in the study of tunnel vibration response analysis. After the Wenchuan earthquake, the vibration response of tunnel portal and shallow tunnels under earthquake vibration ${ }^{[4,5]}$, analysis of Shallow Excavation Tunnel in alluvium under lateral seismic loading ${ }^{[6]}$, the influence of liquefiable site, depth and section on aseismic performance of shallow tunnels ${ }^{[7,8]}$ and others are all studied in detail based on the finite difference method. Based on finite difference software named FLAC/FLAC 3D, Huang et al. ${ }^{[9]}$ studied the dynamic time-history response of a shallow bias tunnel under horizontal seismic action. Kun et al. ${ }^{[10]}$ studied the danger zone around the shallow tunnel in the weak fault zone by numerical simulation and determined the influence of the tunnel on the ground construction. Amorosi et al. ${ }^{\text {[11] }}$ used numerical simulation to explore the destruction area of lining structure of shallow tunnel in a soft soil under earthquake.

There is no specific mathematical function in the study of the relationship between surrounding rock acceleration and stratum under earthquake and there is relatively little research on the horizontal displacement of surrounding rock. Therefore, the dynamic response of the shallow soft rock tunnel under earthquake is calculated by using the finite element software MIDAS/GTS in this paper. The distribution of surrounding rock acceleration along the stratum, the horizontal displacement's change and the stress characteristic of the lining structure are all analyzed to provide some beneficial reference for seismic research, safety construction and stable operation of shallow and soft rock tunnels in the future.

\section{Numerical Modeling}

\subsection{Basic Assumption}

The tunnel is surrounded by surrounding rock and its movement and deformation are both limited. The seismic performance of the tunnel is closely related to the properties of the surrounding rock. In order to better reflect the vibration characteristic of shallow tunnels under earthquake and make the numerical simulation realistically approximate the force of the tunnel in actual project, some assumptions and appropriate simplifications of the calculation model are needed. They will be used in model as follows:

(1)The soil layer is homogeneous, continuous and isotropic and it must comply with Mohr-Coulomb yield criterion during the modeling process. (2)A two-dimensional plane strain model is adopted to analyze the nonlinear time-history of tunnel and the groundwater is not put into consideration. (3)Under seismic action, shedding, slipping and cracking of the interface between the tunnel lining and the surrounding rock are all not considered. (4)The seismic response of shallow tunnel during operation is analyzed while the influence of the construction phase is not considered. (5)The influence of horizontal seismic waves on the tunnel structure-soil is mainly considered while the influence of vertical seismic waves is ignored in the numerical simulation process.

\subsection{Calculation Model}

The tunnel is from a highway that its section is horseshoe-shaped and its lane form is single-hole and two-lane. The cross-section of tunnel is shown in Figure 1. The tunnel's width is $10 \mathrm{~m}$, the maximum burial depth is $10 \mathrm{~m}$, the lining support structure is C20 shotcrete, the lining thickness is taken as $0.3 \mathrm{~m}$, and the surrounding rock's grade is $\mathrm{V}$. The calculation range of the model whose value is the hole diameter's 3 times and equal to $70 \mathrm{~m}$ is expanded along the right and left of the tunnel in the $\mathrm{x}$-axis direction. It also extends down to the arch bottom along the $\mathrm{y}$-axis direction and its value is 
equal to 50m.The $\mathrm{x}$-axis direction is the incident direction of the horizontal seismic wave.

In the numerical model, the constitutive model of the surrounding rock is simulated by 2D plane strain element of the M-C elastic-plastic model, and the constitutive model of the shotcrete lining is simulated by rectangular 1D beam element of the elastic model. When horizontal earthquake occurs, vertical shedding and sliding between the surrounding rock and the lining supporting structure do not appear, so the contact between the surrounding rock and the lining is not taken into consideration. And the surrounding rock and the lining are coupled by capturing unit.

In the nonlinear dynamic calculation, the grid's shape and size interact with the frequency and velocity of the input seismic wave. If the grid is not properly divided, the propagation of seismic wave may be affected and even distorted. Therefore, the reasonable division of grid shape and size is particularly important. The grid shape of this numerical simulation is quadrilateral, and the principle which around the tunnel is small and the model boundary is larger should be followed in the grid division of surrounding rock. The minimum grid size of the tunnel is $0.4 \mathrm{~m}$, and the maximum grid size of the model boundary is $1.25 \mathrm{~m}$. The grid size gradually will become larger as it moves away from the tunnel structure.

\subsection{Mechanical Parameters}

The static mechanical parameters of the lining and the V-grade surrounding rock are shown in Table 1.

Table 1 Staticmechanical Parameters of Model Materials ${ }^{[12]}$

\begin{tabular}{cccccc}
\hline Materials & $\begin{array}{c}\text { density } \\
\left(\mathrm{g} / \mathrm{cm}^{3}\right)\end{array}$ & $\begin{array}{c}\text { Elastic } \\
\text { modulus } \\
(\mathrm{GPa})\end{array}$ & $\begin{array}{c}\text { Poisson } \\
\text { ratio }\end{array}$ & $\begin{array}{c}\text { Cohesion } \\
(\mathrm{KPa})\end{array}$ & $\begin{array}{c}\text { Friction } \\
\text { angle } \\
\phi\left(^{\circ}\right)\end{array}$ \\
\hline $\begin{array}{c}\text { surrounding rock } \\
\text { Lining }\end{array}$ & 1.7 & 1.75 & 0.37 & 100 & 35 \\
\hline
\end{tabular}

However, the dynamic parameters need to be used for calculation when performing dynamic nonlinear time-history analysis. Based on the strain rate effect, the dynamic parameters' value of the model should be increased on the basis of the static parameters. Based on more than 20 shaking table test results, Wang Sijing ${ }^{[13]}$ fitted the empirical formula:

$$
E_{s}=0.025 E_{d}^{1.7}
$$

Where $E_{d}$ is the dynamic elastic modulus; $E_{s}$ is the static elastic modulus. In dynamic load loading, Dai Jun ${ }^{[14]}$ cited the existing literature data that the dynamic Poisson's ratio $\mu_{d}$ is equal to 0.8 times of $\mu_{s}$.

$$
\mu_{d}=0.8 \mu_{s}
$$

where $\mu_{d}$ and $\mu_{s}$ are dynamic Poisson's ratio and static Poisson's ratio respectively.

The mechanical parameters of the lining will be also changed under earthquake. Referencing to the relevant research methods, this numerical modeling increased the elastic modulus of the lining by $25 \%$ and the Poisson's ratio by $20 \%$ on the original basis. The dynamic elastic modulus and dynamic Poisson's ratio of the surrounding rock are converted according to formulas 1 and 2, and the dynamic parameters of the surrounding rock and lining after conversed are shown in Table 2. 
Table 2 Dynamic Mechanical Parameters of Model Material

\begin{tabular}{cccccc}
\hline Materials & $\begin{array}{c}\text { Bulk density } \\
\left(\mathrm{kN} / \mathrm{m}^{3}\right)\end{array}$ & $\begin{array}{c}\text { Elastic } \\
\text { modulus } \\
(\mathrm{GPa})\end{array}$ & $\begin{array}{c}\text { Poisson } \\
\text { ratio }\end{array}$ & $\begin{array}{c}\text { Cohesion } \\
(\mathrm{kPa})\end{array}$ & $\begin{array}{c}\text { Friction } \\
\text { angle } \\
\phi\left(^{\circ}\right)\end{array}$ \\
\hline $\begin{array}{c}\text { surrounding rock } \\
\text { Lining }\end{array}$ & 17 & 12.17 & 0.30 & 100 & 35 \\
\hline
\end{tabular}

\subsection{Application of Boundary Conditions}

At present, for the dynamic load problems such as earthquake, artificial boundaries applied in tunnels and underground structures mainly include viscous, viscoelastic and transmission boundaries. Because the viscoelastic boundary can not only constrain the zero-frequency component in the dynamic problem but also simulate the elastic restoring force of the semi-infinite medium outside the artificial boundary, it has good stability and high precision. Therefore, the viscoelastic artificial boundary is used in the numerical calculation process in this paper. During the numerical modeling process, the viscoelastic artificial boundary is simulated by creating curved spring, and the tangential and normal ground reaction coefficients and damping constants of the curved spring are calculated according to formula $3^{[15]}$. Among them, the viscoelastic artificial boundary is applied to the lateral boundary of the model. Since the bottom boundary of the model is far away from the tunnel structure, it is taken as a fixed boundary where the seismic wave acceleration time-history can be input, and its surface is a free deformation boundary without any constraints. The mesh and surrounding boundary of the model are shown in Figure 2.

$$
K_{T}=\alpha_{T} \frac{G}{R} ; C_{T}=\rho c_{s} ; K_{N}=\alpha_{N} \frac{G}{R} ; C_{N}=\rho c_{p}
$$

In the formula: $c_{p}=\sqrt{\frac{\lambda+2 G}{\rho}}, c_{s}=\sqrt{\frac{G}{\rho}}, \lambda=\frac{E \mu}{(1+\mu)(1-2 \mu)}, G=\frac{E}{2(1+\mu)}$.

The parameter $\alpha_{s}$ and $\alpha_{N}$ are the correction factors for tangential and normal directions and their range of value is $[0.35,0.65]$ and $[0.8,1.2]$ respectively. The parameter $c_{s}$ and $c_{p}$ are the wave speed of s-wave and p-wave, respectively. $\mathrm{G}$ is the shear modulus; $\lambda$ is the volumetric elasticity coefficient; $\mathrm{E}$ is the elastic modulus; $\mu$ is the Poisson's ratio; $\rho$ is the density of the medium; $\mathrm{R}$ is the dynamic effect which is produced because of the distance from the artificial boundary to the location of the load.

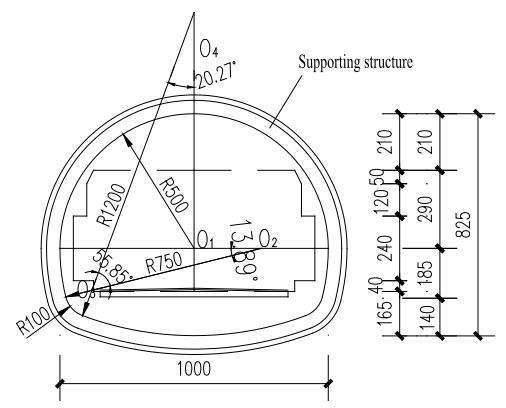

Fig.1 Tunnel section (unit: cm)

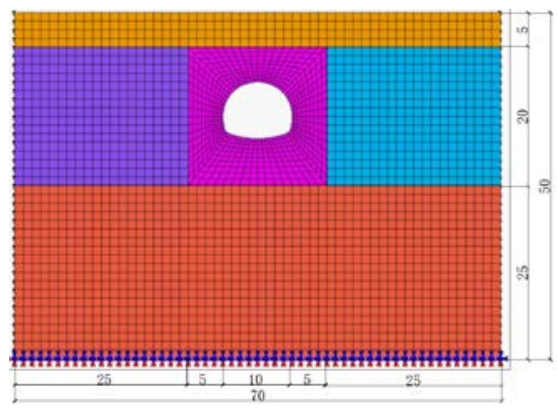

Fig.2 Calculation model for shallow tunnel (unit: m) 


\section{Damping Ratio and Seismic}

\subsection{Damping Ratio Determination}

Damping is generally divided into internal damping and external damping in engineering. Internal damping refers to the energy consumed by the internal friction of the materials such as heat energy, while external damping is mainly caused by the energy loss caused by the sliding friction between two solid surfaces. The most important external damping is the viscous damping, which is widely used due to its easiness to be handled by mathematical methods.

In dynamic analysis, Rayleigh damping is widely used in practical engineering because of its convenient calculation, saving memory and calculation precision, so it can basically meet engineering and research requirement. Rayleigh damping can be calculated by the following formula:

$$
[\mathbf{C}]=\alpha[\mathbf{M}]+\beta[\mathbf{k}]
$$

In the formula: $[\mathrm{C}]$ is the damping matrix; $[\mathrm{M}]$ is the mass matrix; $[\mathrm{K}]$ is the stiffness matrix; the parameters $\alpha, \beta$ are the damping coefficients respectively, which can be both calculated via the $\mathrm{f}$ formula $\xi=\exp (\alpha \beta)$, where $\xi$ is the damping ratio. In the numerical simulation, when the damping ratio $\xi$ is equal to 0.05 , it can satisfy the numerical calculation accuracy.

\subsection{Seismic Wave Selection}

During dynamic analysis' process, the reasonable selection of seismic wave is an important precondition to ensure the reliability of the calculation results. If the main parameters of ground motion can be correctly selected, the seismic response of structures under earthquake action can be more accurately reproduced ${ }^{[16]}$. The EL Centro and Wenchuan seismic wave are mainly used as the seismic load input in the numerical simulation. The peak acceleration of the EL wave is scaled down to $0.04 \mathrm{~g}, 0.08 \mathrm{~g}, 0.12 \mathrm{~g}$ and $0.16 \mathrm{~g}$ for loading, and the peak acceleration of the Wenchuan wave is scaled down to $0.1 \mathrm{~g}, 0.2 \mathrm{~g}, 0.3$ gand $0.4 \mathrm{~g}$ for loading. The duration $\mathrm{T}$ of seismic wave excitation should be selected as long as possible and contain the strongest part of the seismic record. It is generally recommended that $\mathrm{T}$ should be greater than or equal toT1which is the basic cycle of the structure. Therefore, the duration of the two seismic waves selected for this numerical calculation is 20secs including the record of strong earthquakes, in which the EL wave is the first 20sec and the Wenchuan wave is $10-30$ sec, as shown in Fig.3.

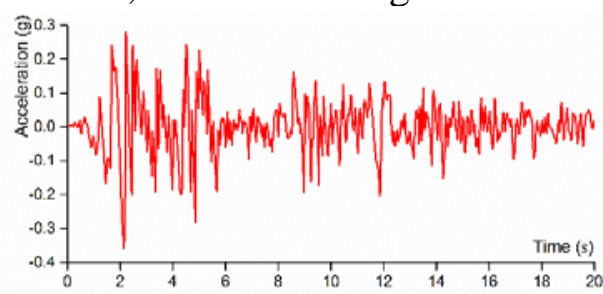

(a) EL Centro wave



(b) Wenchuan wave

Fig.3 Acceleration time history of seismic waves

\subsection{Computational Solution}

The numerical calculation needs to consider the self-weight and earthquake action. Before the dynamic analysis, it is necessary to add a linear static analysis with only the gravity load to obtain the 
initial stress field. In the dynamic analysis control, model calculation is needed to define the damping. Therefore, the eigenvalue analysis is required to calculate the natural vibration period of the top two modes. In addition to applying the fixed boundary at the bottom, the eigenvalue analysis also requires adding a horizontal bed coefficient on both sides of the model without any damping or load. For the soil mass, the period of top two modes with the largest mass participation coefficient in the x-axis direction is used. The results of the eigenvalue analysis are shown in Table 3. The results show that the mass participation coefficients of the first and third vibration modes are the highest, reaching $69.86 \%$ and $11.98 \%$ respectively, and the natural vibration periods of the top two modes are $0.274 \mathrm{sec}$ and 0.176 sec respectively.

Table 3 Eigenvalue Analysis Results

\begin{tabular}{cccccc}
\hline $\begin{array}{c}\text { Mode } \\
\text { number }\end{array}$ & $\begin{array}{c}\text { Mass participation } \\
\text { coefficient /x-axis }\end{array}$ & Period/Sec & $\begin{array}{c}\text { Mode } \\
\text { number }\end{array}$ & $\begin{array}{c}\text { Mass participation } \\
\text { coefficient /x-axis }\end{array}$ & $\begin{array}{c}\text { Period/Se } \\
\text { c }\end{array}$ \\
\hline 1 & $71.28 \%$ & 0.274 & 6 & $0.00 \%$ & 0.105 \\
2 & $0.00 \%$ & 0.182 & 7 & $1.37 \%$ & 0.0867 \\
3 & $11.31 \%$ & 0.176 & 8 & $0.00 \%$ & 0.0795 \\
4 & $0.00 \%$ & 0.137 & 9 & $0.50 \%$ & 0.0762 \\
5 & $5.56 \%$ & 0.110 & 10 & $0.00 \%$ & 0.0724 \\
\hline
\end{tabular}

\subsection{Acceleration Characteristics}

The acceleration response of tunnels and surrounding rocks under loading of EL waves are sorted out by numerical calculations respectively, as shown in Figure 4-5. The figures show that the acceleration time-history of the lining vault and surrounding rock is almost the same under the earthquake. That is, the characteristic of the acceleration distribution is the same which indicates that the tunnel structure has obvious follow-up to the vibration of the surrounding rock; The peak acceleration of the vault is greater than that of the invert and all greater than the peak acceleration input at the bottom of the model; The acceleration of the surrounding rock above the vault has a amplifying effect with the decrease of distance from the surface, and the surface is about $50 \%$ larger than the vault. The acceleration of the surrounding rock around the tunnel decreases with the increase of distance from the tunnel, and acceleration at lateral $20 \mathrm{~m}$ is only $90 \%$ of the vault. The increase or decrease of the surrounding rock's acceleration whether in the vertical direction or in the lateral direction as it moves away from the tunnel is not obvious when the peak acceleration is small which indicates that the acceleration response of the surrounding rock in the earthquake is not severe when the seismic intensity is small.

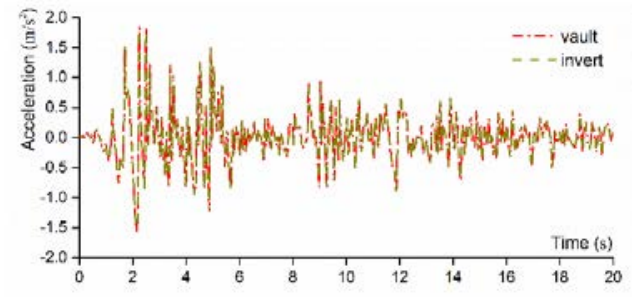

(a) Tunneling lining

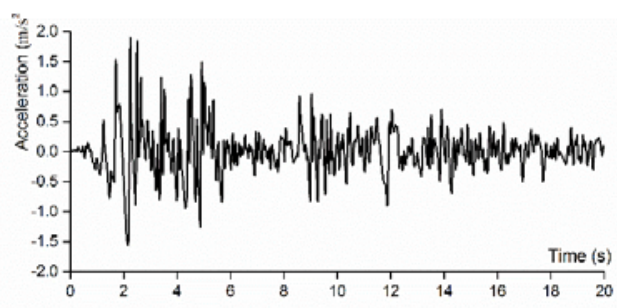

(b) Surrounding rock at vault

Fig.4 Acceleration time history of tunnel and surrounding rock（PAG=0.16g） 


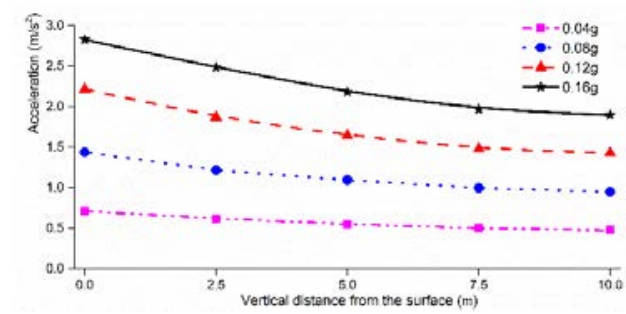

(a) Along the vertical direction



(b) Along the lateral direction

Fig.5 The variation of acceleration of the surrounding rock

\subsection{Surrounding Rock Deformation Law}

The surrounding rock has obvious horizontal relative displacement under earthquake action, and the horizontal displacement of the surrounding rock under the loading of the EL wave is shown in Figure 6. It shows that the horizontal relative displacement of the surrounding rock is related to the peak acceleration of the seismic wave and the height of the strata. The value gradually increases with the decrease of the distance from the surface and reaches the maximum value in the ground, and increases with the increase of the seismic intensity. The maximum horizontal relative displacement of surrounding rock is about $0.140 \mathrm{~mm}$ and $0.588 \mathrm{~mm}$ when the peak acceleration is $0.04 \mathrm{~g}$ and $0.16 \mathrm{~g}$ respectively.

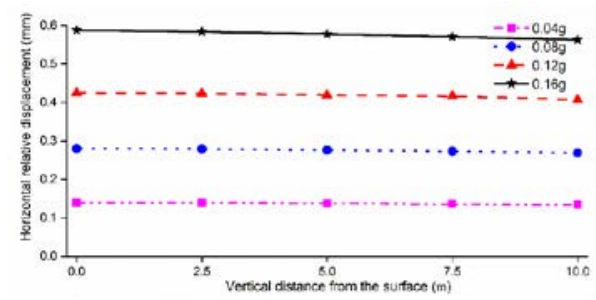

Fig.6 The variation of horizontal relative displacement along the vertical direction

The surrounding rock at the lateral $10 \mathrm{~m}$ around the tunnel is the zero displacement point, and the horizontal displacement of the surrounding rock, which is relative to the zero displacement point, within $10 \mathrm{~m}$ around the tunnel is shown in Figure7. It shows that the horizontal displacement of the surrounding rock at the vault is larger than it at the hance, which generally increases by about $8 \%$ and keeps decreasing when its location moves away from the tunnel.

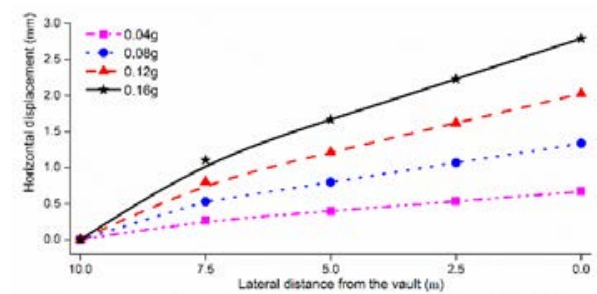

(a) Around the vault

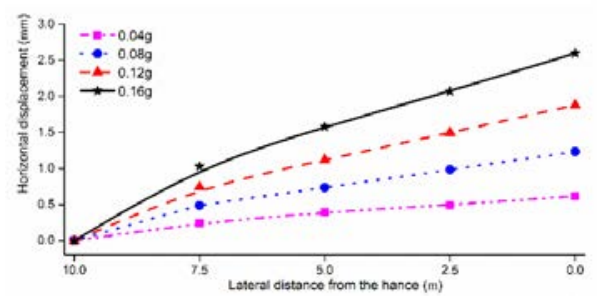

(b) Around the hance

Fig.7 Horizontal displacement of surrounding rock around the tunnel

\subsection{Internal Force Distribution of Lining}

The internal force cloud map of lining structure under loading of self-weight and peak acceleration of $0.1 \mathrm{~g}$ is shown in figure 8 9 respectively. It shows that the lining structure's axial force and bending moment is symmetrical under the action of self-weight. Among them, the spandrel to arch foot is 
subject to negative bending moments and the rest are subject to positive bending moments. Under the action of seismic load, the lining structure is anti-symmetrically stressed, such as axial force and bending moment. The internal forces of the spandrel and arch foot are significantly greater than that of the vault, hance and inverted arch.

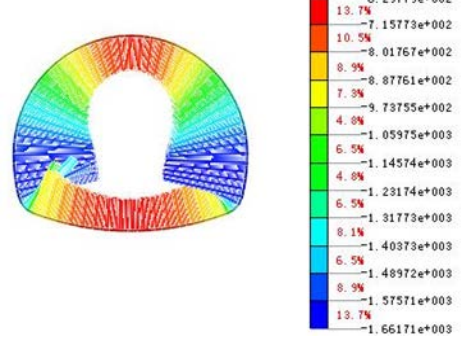

(a)Axial force

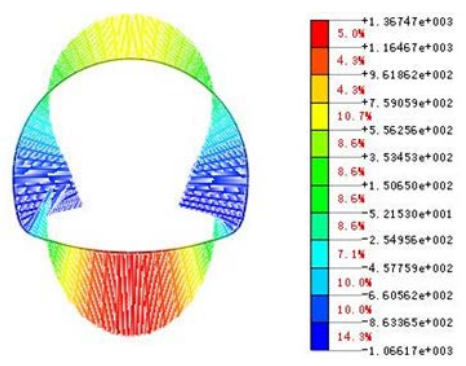

(b) Bending moment

Fig.8 Initial force cloud diagram of lining $(\mathrm{PAG}=0)$

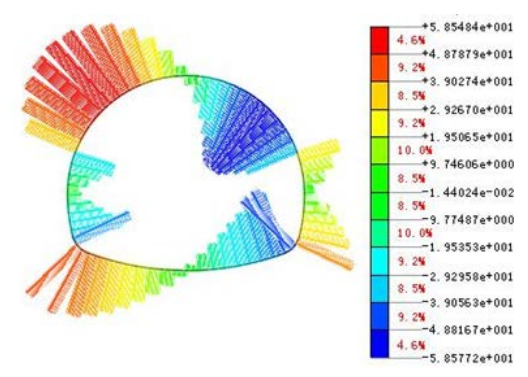

(a)Axial force

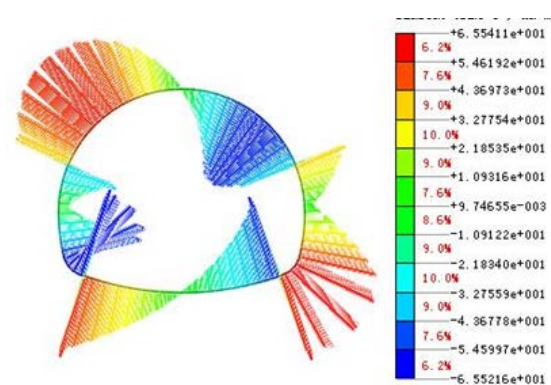

(b) Bending moment

Fig.9 Force cloud diagram of lining ( $\mathrm{PAG}=0.1 \mathrm{~g})$

Under the load of each peak acceleration of Wenchuan wave, the force range of the lining structure is shown in figure 10 11. It shows that the lining structure is subjected to cyclic internal forces under the action of small earthquake, such as: the force in tension and compression and the bending moment in positive and negative. With the strengthening of the seismic intensity, the axial tension force near the lining vault, arch foot and inverted arch gradually becomes pressure, and the sagging moment near the lining vault and the hance gradually becomes negative bending moment. The peak internal force of the lining structure increases with the increase of the seismic intensity, and the change of internal force is most obvious at spandrel and arch foot.

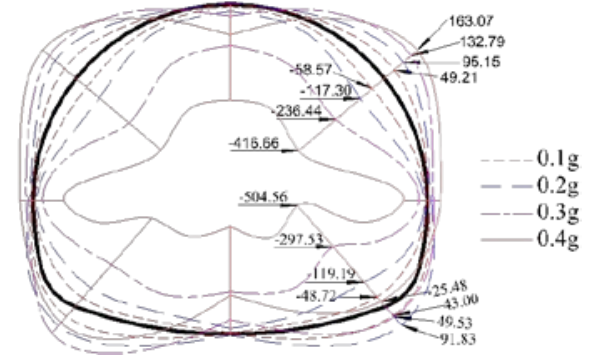

Fig.10 The axial force range of linings (KN)

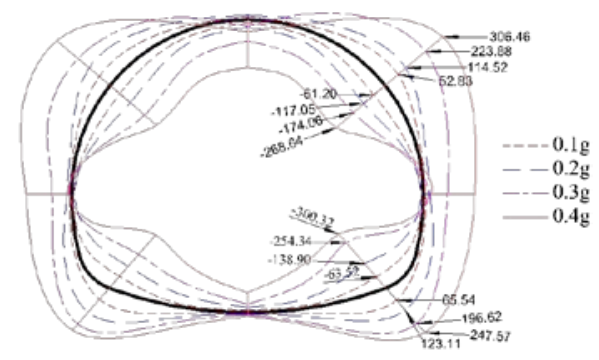

Fig.11 The bending moment range of lining $\left(\mathrm{KN}^{*} \mathrm{~m}\right)$

\section{Conclusion}

In this paper, with the help of the finite element software MIDAS/ GTS, the initial stress analysis, eigenvalue analysis and nonlinear dynamic time-history analysis are all carried out for shallow soft surrounding rock tunnels by setting reasonable artificial boundary and inputting reasonable seismic 
waves. The main conclusions can be obtained as follows:

(1) The acceleration of the surrounding rock increases in the vertical direction as it approaches the surface while it will decrease in the lateral direction when it moves away from the tunnel. The ground acceleration is about 1.5 times than vault acceleration, and the acceleration value at tunnel lateral $20 \mathrm{~m}$ is only $90 \%$ of vault's acceleration value.

(2) The horizontal relative displacement of surrounding rock is obvious under earthquake action. It will increase with the decrease of the distance from the surface in the vertical and reach the maximum value in the ground. The deformation value of surrounding rock near the vault is about 1.08 times than near the hance, and the horizontal displacement of the surrounding rock around the tunnel gradually decreases as it moves away from the tunnel.

(3)The earthquake changes the initial stress state of the lining structure and the lining structure is subjected to cyclic internal forces under the action of small earthquakes. The maximum axial force and bending moment appear at the spandrel and the arch foot respectively, so the anti-seismic design should be strengthened.

\section{Acknowledgments}

This work was financially supported by Scientific Reserch Fund of SiChuan Provincial Education Department of China (11ZB055).

\section{References}

[1] CUI Guangyao, WU Xiugang, WANG Mingnian, et al. Earthquake Damages and Characteristics of Highway Tunnels in the 8.0-Magnitude Wenchuan Earthquake [J]. Modern Tunnelling Technology, 2017,54(2):9-16.

[2] LIU Liyu, CHEN Zhiyi, YUAN Yong. Impact of Rock Class on Seismic Responses of Mountain Tunnels under Severe Earthquakes [J]. Chinese Journal of Underground Space and Engineering, 2011, 07(s1):1314-1318.

[3] CUI Guangyao, LIU Weidong, NI Songzhi, et al. Study on Different Seismic Intensities and Earthquake Damage to Highway Tunnels in Wenchuan Area Affected by Earthquakes[J].Modern Tunnelling Technology, 2014,51(6):1-6.

[4] Geniş M. Assessment of the dynamic stability of the portals of the Dorukhan tunnel using numerical analysis [J]. International Journal of Rock Mechanics \& Mining Sciences, 2010, 47(8):1231-1241.

[5] Shen Y, Gao B, Yang X, et al. Seismic damage mechanism and dynamic deformation characteristic analysis of mountain tunnel after Wenchuan earthquake [J]. Engineering Geology, 2014, 180:85-98.

[6] Argyroudis S A, Pitilakis K D. Seismic fragility curves of shallow tunnels in alluvial deposits [J]. Soil Dynamics \& Earthquake Engineering, 2012, 35:1-12.

[7] Mobaraki B, Vaghefi M. Numerical study of the depth and cross-sectional shape of tunnel under surface explosion [J]. Tunnelling and Underground Space Technology incorporating Trenchless Technology Research, 2015, 47:114-122.

[8] Azadi M, Hosseini S M M M. Analyses of the effect of seismic behavior of shallow tunnels in liquefiable grounds [J]. Tunnelling \& Underground Space Technology Incorporating Trenchless Technology Research, 2010, 25(5):543-552.

[9] Huang J, Peng L M, Lei M F, et al. Seismic response and capacity safety analysis of shallow-embedded bias tunnels with small clear distance [J]. Journal of Railway Science \& Engineering, 2012.

[10] Kun M, Onargan T. Influence of the fault zone in shallow tunneling: A case study of Izmir Metro Tunnel [J]. Tunnelling \& Underground Space Technology Incorporating Trenchless Technology Research, 2013, 33(1):34-45.

[11] Amorosi A, Boldini D. Numerical modelling of the transverse dynamic behaviour of circular tunnels in clayey soils [J]. Soil Dynamics \& Earthquake Engineering, 2009, 29(6):1059-1072.

[12] Concrete structure design specification[S].China Building Industry Press, 2011.

[13] Wang Si-jing, Tang Da-rong, Yang Zhi-fa, et al. Preliminary application of acoustic wave technology in engineering rock mass testing [J].Chinese Journal of Geology, 1974, 9(3):269-282.

[14] Dai Jun. Rock dynamics and blasting theory [M]. Metallurgical Industry Press, 2002.

[15] LIU Jing-bo GU Yin DU Yi-xin. Consistent viscous-spring artificial boundaries and viscous-spring boundary elements [J]. Chinese Journal of Geotechnical Engineering, 2006, 28(9):1070-1075.

[16] GB50011-2001, Seismic design specification for buildings[S]. Building Industry Press, 2006. 